\title{
Facebook impacting in healthcare service quality Case study in AL-Baseer eyes diseases center
}

\author{
*Samaa A. AL-Zubaidy, ** Sadoon H. AL-Rubeawee \\ *Assistant Lecturer , Al Israa Private University College \\ **Assistant Professor, College of Management and Economics, University of Baghdad,
}

\begin{abstract}
The research problem lies in finding out how Facebook impacts healthcare service quality. The goal is identify the share of this web media in presenting health information and its role in building the trust between the medical team and its patients. Thus, an overview is made to identify research dimensions and other researchers' views about them. A written questionnaire was devised which was answered by 60 sample respondents who already had experience with Center. They were asked about the suitability of Center location and the quality of service the Center offers. In addition a questionnaire was posted on the Center e-page on Facebook site which included questions on the e-page and the information is offers and interview was made with center's manager Dr.Muhannad AL-Mayali to discuss some matters with him to get accurate information and results, that were discussed on which recommendations were offered.
\end{abstract}

Key words: Facebook, page, health care, patient, quality

\section{Introduction:}

The world and Iraq in particular have witnessed an increasing use of social, especially Facebook web, which became important part in every person's life, both in work environment and communication with family and friends, which has an effect on all aspects of life whether positive or negative. Health care service is one of the important elements in human life, this effect is reflected in health care service, nearly every social media covers or deals with some aspects of health.

\section{Problem:}

In the light of what has already been said, the research problem is summarized in these questions

1- Has Facebook contributed to dissemination of any modern health services?

2- Have the medical pages contributed to building trust among medical team and their patients?

3- Do the pages visitors accept to visit a medical center known to them through e-page?

Goals:

Research aims to get firsthand knowledge of the importance of e-pages on Facebook to improve health care service offered, and the extent of their contribution to familiarizing the new technologies in treatment.

\section{Hypothesis:}

The Research seeks to prove two main hypotheses in terms of research results:

First: There is a significant correlation between Facebook and the quality of health service

Second Facebook has a significant effect on the quality of health service

\section{Data collection method:}

Three methods were used to collect data

A questionnaire has been set, containing a number of questions on the research objective prepared by the researchers, questions were on health care service .The resource of questions was (Marshall \& Hays. 1994) study.

The second tool was a questionnaire; this questionnaire is based on the studies of (Sintset, 2012) and (Ansari-Dunkes \& Enckevort, 2013. It consists of questions about using Facebook and center's page.

The third tool was interviewing center manager, the interview consisted of questions based on the study of (Korosuo, 2013) study

\section{Community and simples:}

The research was performed at AL-Baseer Center which is specialized to treat eye diseases and Lasik vision correction by use of advanced techniques. The Center was founded in June/2013 in Baghdad city; because of its novelty has good reputation 
The center's teamwork has gained people's trust, although there other centers in Baghdad with same specialization.

During the research period, 280 people visited the Center most of them have visited the Center previously. 100 questionnaire forms were distributed among them. These respondents were selected because they are familiar with the doctors and work team. Only 60 patients responded. Table (1) shows their characteristics

Table (1) Sample characterizes

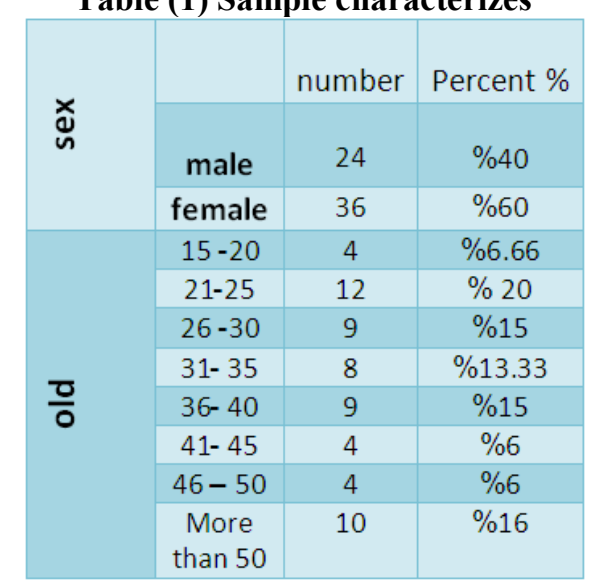

\section{Sincerity and Validity Test}

Validity and reliability are the necessary conditions needed to build tests and standards, Reliability means the property of a tool to measure what it is aimed to measure so Cronbach Alpha is used to determine the degree of Reliability of the measuring tool. In this study and prior to recording the standard level when Cronbach Alpha reaches the lowest acceptable value of $(0.611)$. The quality performance has been realized when the coefficient Alpha Cronbach has achieved minimum acceptable value which is (60\%), \%), while the sincerity of the scale means the ability of questionnaire form to measure what it is designed for which is measured by the equation (validity $=\sqrt{\text { Reliability }}$ ) which is $(078)$ ), and this mean the questionnaire standards are valid for measuring.

\section{Overview: \\ Facebook:}

Social media have changed the way of communication and interaction between the organizations and individuals. During the recent years, the huge merge of social media has led the companies to change their current marketing strategies into the use of social media marketing. The increasing number of companies adopting this kind of performance has created a need to study this phenomenon (Kalliopi, 2013:3). It is very inexpensive for all types of users, which makes it accessible so that anyone can publish or read information easily. Among these media is Facbook which, for companies, poses a huge potential to attract customers. Companies have two different ways to use Facebook as a marketing platform. The first is an advertising platform offered by Facebook where companies can pay to showcase commercials that are directed at users that might need those products The second platform is that Facebook offers companies a chance for exposure called "pages" which was introduced in 2007. A company starts a Facebook page as an internal website for the company on Facebook (Sandell, 2012:9- ). It is important to understand the power of Facebook lies in its mission. For Facebook it is: "Make the world more open and connected. People use Facebook to stay connected with friends and family, to discover what's going on in the world, and to share and express what matters to them". There are several purposes of using Facebook as a marketing channel for companies. There are several purposes of using Facebook as a marketing channel for companies. Instead of word-of-mouth (wom), which can be a slow way to spread information from friend to friend, Facebook represents online word-of-mouth. It represents online word-of-mouth. This means that Facebook is a way of spreading information, fast through the whole network. There are many other reasons why companies use it, the two main reasons are that it is cheap and an easy way to advertise. Another positive aspect is that companies can try out marketing campaigns and get response from the online consumers before implementing the product to the actual market. According to the response a company receives from its consumers on Facebook, it can be a helpful platform that develops and maintains the relationship. The communication should, therefore, be easy, interesting, relevant, fresh and measured in order to create a successful relationship on Facebook. The success can be measured with how many likes companies have. Like is one important aspect that the companies do not have any control over. And it is a 
way to get the information about what is published and companies should publish what is the attractive and interesting to their customers to keep them connected. Customers want something tangible to interact with the site (Oxwall \& Zander, 2012:10).

It can be concluded that the Facebook is a marketing tool used to advertise and exchange information .however it may have negative or positive feedback acting through customers' reactions to specific product ,and the speed information is disseminated among them through Facebook.

Facebook dimensions as set by (Oxwall \& Zander, 2012:24) are:

Security: is defined on Facebook as a guarantee that the company has given accurate information which the consumer can use in an appropriate way and that adds value to the relationship with the customers. In this dimension, information about the company is of great importance, therefore it should give information about how to connect to it, its location and opening hours. This information should be easy to find for the consumer. In this dimension, reference is made to the language and the way the company can reach the customer through Facebook information The word security also holds for the language, how the companies reach out to the consumer through Facebook. The language and security have to be complemented in order for the consumer to interact with company's Facebook page.

Design: refers to how far the consumers are attracted by the message laid out on the Facebook page. This includes the profile and background picture but also how far the page is compatible

with pictures and information, as well as the effort the company puts on Facebook design. A good design makes the consumer feel secure and the design should hold a professional look in order to attract the consumer. Design is an important element to strengthen the relations with consumer and connect with them.

\section{Healthcare Quality:}

Nowadays, increased competition has influenced both private and public service-oriented organizations everywhere but mostly in developed countries. Therefore, in order to survive, organizations have to deliver services that satisfy customers' needs Purcărea \& et al , $2013: 574)$.For every healthcare delivery, patients are the main users and therefore, patient care is the primary function of every hospital where the dignity and value of each person is respected. Therefore, it is entirely desirable and proper that the views of patients should be sought on their experiences and expectations of healthcare. This has drawn the attention of most hospitals to modify their services to achieve patient satisfaction, in view of this; the hospital has to develop itself technologically, as well as become more service-oriented, to understand the fact that patients do not flock to hospital just because its services are cheap, but because of its good customer service delivery .It is necessary, therefore, that hospitals become organizations permanently controlled by the patients' interest. Interestingly, today's clients are tougher, more informed and also sensitive to poor services, which make them often walk away and never come back for repeated services. Therefore 9 , the quality of service will remain a key success factor in the component of the healthcare delivery in hospital (Essiam, 2013:52). Therefore, dimensions of healthcare performance are those definable, preferably measurable, attributes of the system that are related to its functioning to maintain, restore, or improve healthcare(Arah \& et al , 2006: 8). The customers and their views are standards for determining the quality of the health service, therefore, according to a study by (Marshall \& Hays, 1994) five dimensions determine healthcare service quality. They are:

Technical quality: The equipment used and the physical capacity referred to by (Arah \& et al, 2006) (Untachai, 2012), (Essiam, 2013), (Purcărea \& et al, 2013) as reliability and tangibility

Interpersonal manners: it refers to the manner of dealing with patients and the care given to them, and referred to by (Untachai, 2012), (Essiam, 2013), (Purcărea \& et al, 2013) as empathy.

Financial aspects: It means the ability of the patient to spend a certain amount of money and the extent of exposure to financial pressure to get the health service they need, and is referred to by (Arah \& et al, 2006), (Essiam, 2013) in their studies

Accessibility and convenience: Agreed upon by (Arah \& et al, 2006), (Untachai, 2012), (Purcărea \& et al, 2013), and (Essiam, 2013), which means easy access to the health service.

Time spent with doctor: which is referred to by (Untachai, 2012), (Purcărea \& et al, 2013), and (Essiam, 2013) as (responding to costumer) which means readiness to help patient to gain the service need

\section{Analysis of Results:}

This section includes analyses of data collected about research's dimensions and explains the results. It includes analysis and explanation of frequencies, percent, mean, and standard deviation. The second part includes analysis of correlation among variables, and last part includes analysis of regression among variables. 


\section{First: Presentation, analysis, and explanation of results}

\section{Presentation, analysis, and explanation of results for Facebook}

This dimension is represented by two branch dimensions (security and design). The results of each branch are explained as shown below:

The security branch has achieved a good general mean equal to (3.71) and standard deviation of (0.91) showing homogeneity in answers in general with security items, according to items, item one achieved good mean equal to (3.95) with (36.7\%) strong agreement and (30\%) agreement which shows good description of the centers' E-page give address, the third item achieved good mean equal to (3.73) with (41\%) agreement. This means the center meets the offers which are advertised on its page. It can be regarded as steps to build trust relationship with customers (patients) .

"Design" dimension has achieved good general mean equal to (3.8) and standard deviation of (0.89). Item four has achieved high mean equal to (4.16) with (41.7\%) strong agreement and (36.7\%) agreement which means the cover image and images posted on the page have close relation with the medical service provided by center. The fifth item has achieved mean equal to (4.08) with (35\%) strong agreement and (45\%) agreement that means the Center page gives true information about treatment techniques. The sixth item has achieved acceptable mean equal to (3.16) with (48\%) from answers were neutral .thus, this means respondents don't keep abreast with administrator's answers to their questions or the group that put this item doesn't ask any question on the centers' e-page on the Facebook. The results are shown in Table (2).

Table (2) Description sample to Facebook dimensions

\begin{tabular}{|c|c|c|c|c|c|c|c|c|c|c|c|c|c|}
\hline \multirow{2}{*}{$\underset{z}{z}$} & \multirow[t]{2}{*}{ Items } & \multicolumn{2}{|c|}{$\begin{array}{l}\text { Strongly } \\
\text { disagree } \\
1\end{array}$} & \multicolumn{2}{|c|}{$\begin{array}{l}\text { Disagree } \\
\mathbf{2}\end{array}$} & \multicolumn{2}{|c|}{$\begin{array}{l}\text { Uncertain } \\
3\end{array}$} & \multicolumn{2}{|c|}{$\begin{array}{l}\text { Agree } \\
4\end{array}$} & \multicolumn{2}{|c|}{$\begin{array}{l}\text { Strongly agree } \\
\mathbf{5}\end{array}$} & \multirow{2}{*}{$\frac{E}{E}$} & \multirow[t]{2}{*}{ 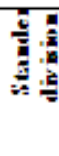 } \\
\hline & & $\%$ & $f$ & $\%$ & $f$ & $\%$ & $f$ & $\%$ & $f$ & $\%$ & $\mathrm{f}$ & & \\
\hline \multicolumn{14}{|c|}{ Security } \\
\hline 1 & $\begin{array}{l}\text { There is an accurate description of the } \\
\text { address of the center on Facebook page }\end{array}$ & 1.7 & 1 & 5 & 3 & 26.7 & 16 & 30 & 18 & 36.7 & 22 & 395 & 099 \\
\hline 2 & $\begin{array}{l}\text { The timing of the opening and closing } \\
\text { posted on the page correspond to times of } \\
\text { the Centre's work actually }\end{array}$ & - & - & 20 & 12 & 30 & 18 & 33.3 & 20 & 16.7 & 10 & 3.46 & 099 \\
\hline 3 & $\begin{array}{l}\text { Implemented offers advertised on the } \\
\text { Facebook page actually }\end{array}$ & - & - & 1.7 & 1 & 40 & 24 & 41.7 & 25 & 16.7 & 10 & 3.73 & 0.75 \\
\hline \multicolumn{12}{|c|}{ General Mean and the standard deviation } & 3.71 & 0.91 \\
\hline \multicolumn{14}{|c|}{ Design } \\
\hline \begin{tabular}{l|l}
4 \\
\end{tabular} & $\begin{array}{l}\text { Cover photo and photos posted on the } \\
\text { center page on F acebook closely related } \\
\text { to its services, including medical. }\end{array}$ & - & - & 33 & 2 & 18.3 & 11 & 36.7 & 22 & 41.7 & 25 & 4.16 & 0.84 \\
\hline 5 & $\begin{array}{l}\text { The center provides accurate } \\
\text { information about the methods and } \\
\text { techniques of treatment provided. }\end{array}$ & - & - & 6.7 & 4 & 13.3 & 8 & 45 & 27 & 35 & 21 & 4.08 & 0.86 \\
\hline 6 & $\begin{array}{l}\text { The admin answer the questions asking } \\
\text { on the page at suitable time }\end{array}$ & 5 & 3 & 15 & 9 & 48.3 & 29 & 21.7 & 13 & 10 & 6 & 3.16 & 097 \\
\hline \multicolumn{12}{|c|}{ General Mean and the standard deviation } & 3.8 & 0.89 \\
\hline
\end{tabular}

Representation, analysis, and explanation of results of healthcare service

This dimension is represented by five branch dimensions, that is, (Technological quality, Interpersonal manners, Financial aspects, Accessibility and convenience and Time spent with doctor). The results are explained as follows

The general mean for Technological quality is equal to (3.6) and standard deviation (0.8) shows homogeneous answers in general about dimensions of items. According to items, item seven has achieved good mean equal to (4.65) with (65\%) strong agreement which explains the center uses developed techniques to provide the service that patients need, the ninth item has achieved good mean equal to (4.5) with (58\%) strong agreement which means patients get proper care with medical checkup.

"Interpersonal manners" is the second dimension which has achieved general mean equal to (3.91) which is a good indicator of response to dimensions' items. The arithmetic mean is equal to the two items (eleven and twelve) (3.91) which represent a good response to the questions. The answer average for eleventh item is $(43.3 \%)$ with strong agreement and $(31.7 \%)$ for agreed, that means almost $(75 \%)$ of answers show the doctor acts formally in the treatment situations. The twelfth item has achieved answer average of (36.7\%) with strong agreement and (41.7\%) agreed, that mean almost $(78 \%)$ of the responders agree the doctor acting with treatment situations friendly and courtesy. Thus, according to results we can say "the responsible doctor at the center acts neutrally and at the same time acts humanely and with respect with patients and that made the patients feel at rest".

The third dimension (Financial aspects) has achieved general mean equal to (3.35) which is a good indicator to the response. The thirteenth item achieve high mean equal to (4.2) with (51.7\%) strong agreement, 
that is according to the viewpoint of customers, treatment price is suitable compared with competitors in the same domain and it doesn't put patients under financial pressure.

The fourth dimension (Accessibility and convenience) has achieved acceptable mean equal to (3.2) which is an indicator to the response. According to items, item fifteen has achieved high mean equal to (4.25) with $(50 \%)$ strong agreement and $(35 \%)$ agreement that means there is compatibility between address description on the Center's' page on the Facebook and advertisements that makes easy access to the Center so that patients get the service they need.

The eighteenth item has achieved mean equal to (3.98) which shows homogeneous answers with (36.7\%) strong agreement and $(33.3 \%)$ agreed. This shows acceptable ratio indicating the patients think they get the service at the time they ask.

The fifth dimension (Time spent with doctor) has achieved general mean equal to (3.15) which is a good guide to response, the twentieth item has achieved high mean equal to (4.58) with (70\%) strong agreement and $(25 \%)$ agreed. That means the responders think the doctor gives enough time to each patient to treat his $/$ her case. Table (3) shows the results.

The eighteenth item achieve mean equal (3.98) was show homogeneous answers with (36.7\%) strong agreement and (33.3\%) agreement this show acceptable ratio about the patients view their get the service at the time they ask .

The fifth dimension (Time spent with doctor) achieve general mean equal (3.15) a good guide to respond, the twentieth item achieve high mean equal (4.58) with (70\%) strong agreement and (25\%) agreement. That's mean the responders find the doctor give enough time to each patient to treat his situation. Table (3) shows the results.

Table (3) Description sample to health care dimensions

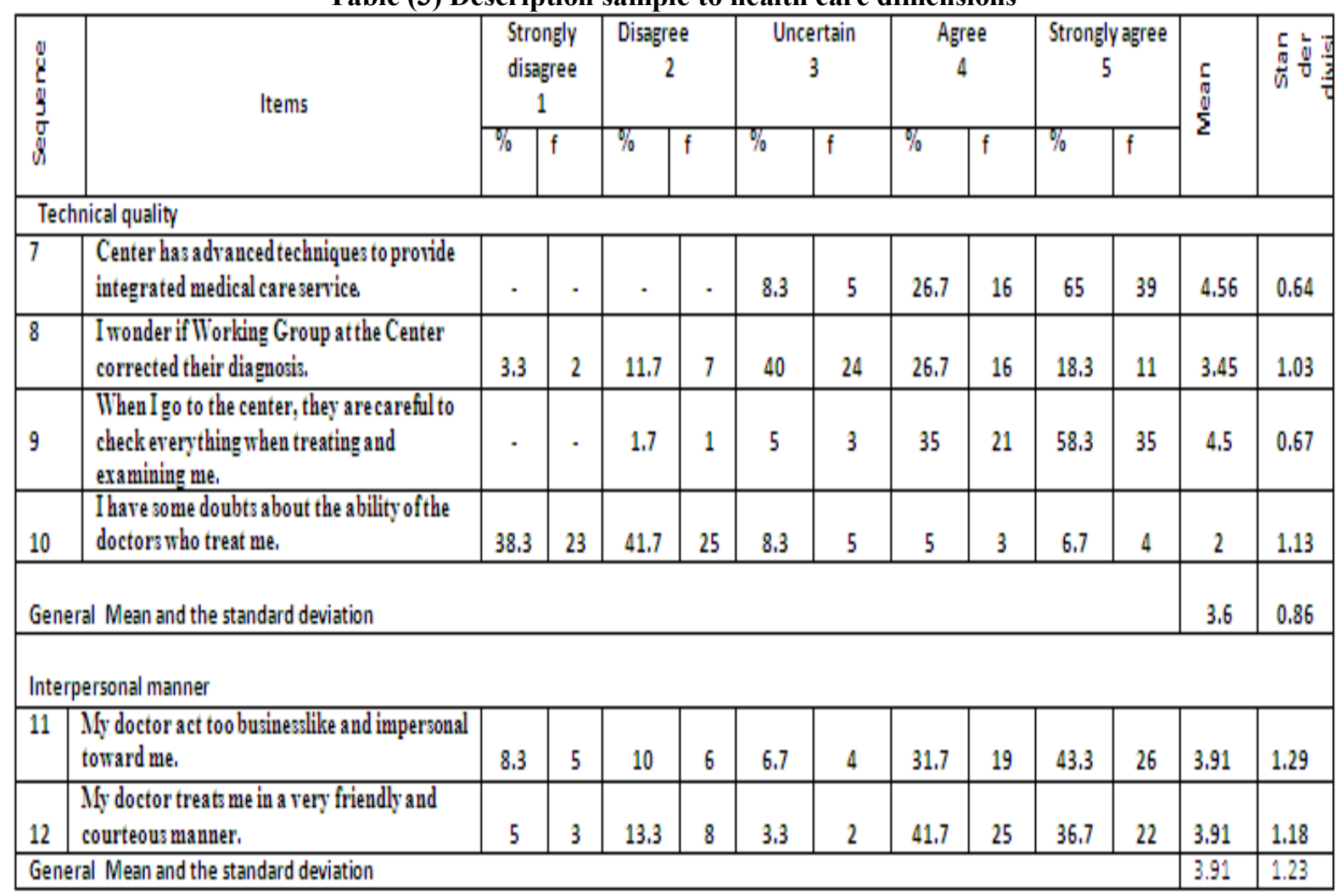


Facebook impacting in healthcare service quality

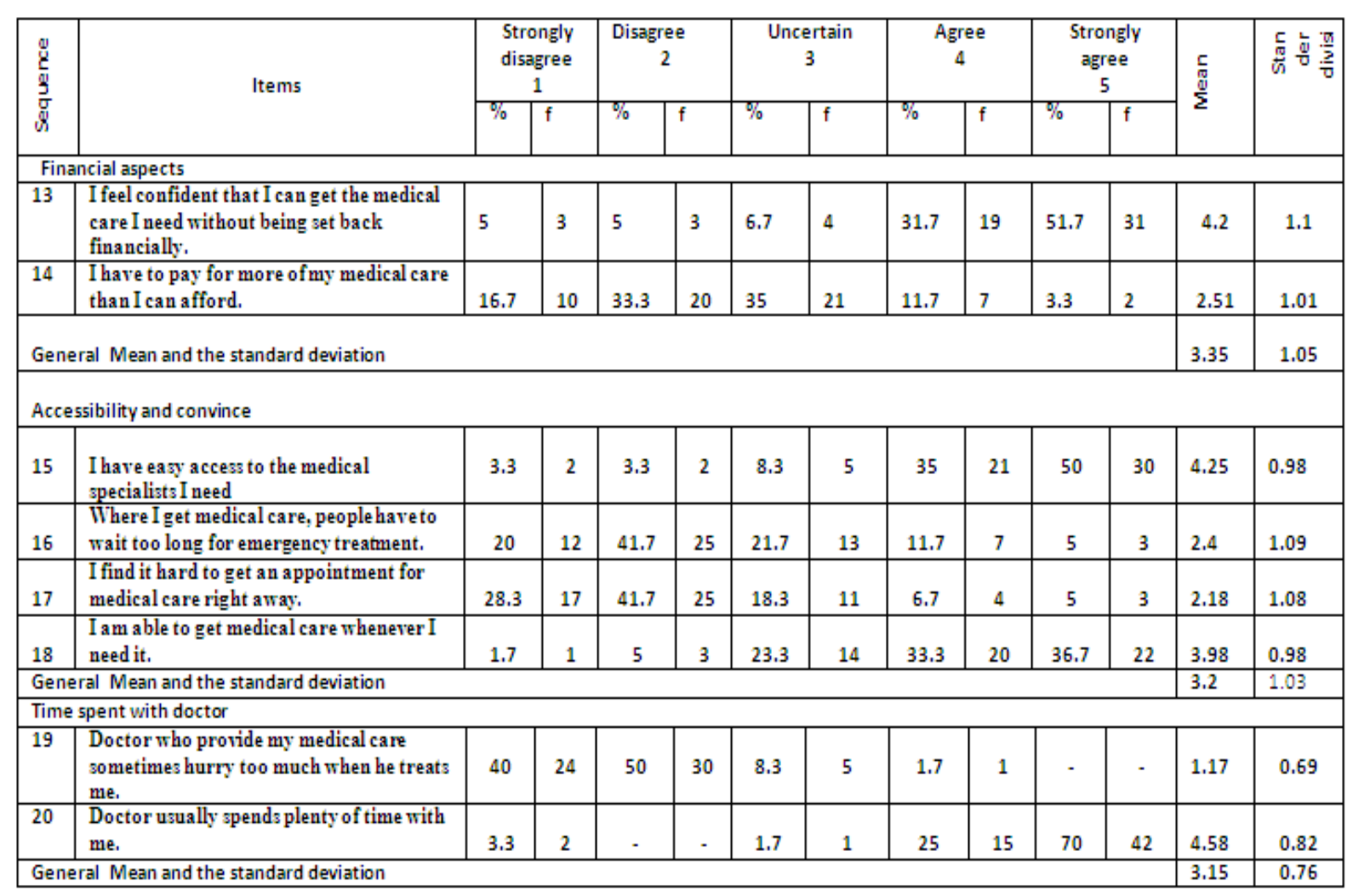

\section{Second: Analysis of the Correlation among Variables}

According to the first main hypothesis which states there is a significant correlation between Facebook and the quality of health service and using the correlation coefficient (Spearman) shows strong correlation in general among the variables equal to $(0.352)$ at total level and to $(0.01)$ at the level of significance. This proves the above-mentioned hypothesis.

With individual dimensions three correlations were achieved making up $(60 \%)$ at the level of significance. The first was $(0.01)$ at the level of significance with technological quality dimension. The correlation is equal to $(0.41)$. That means the page aim focuses on defining the technology used to provide service by work team at the level of significance at the Center.

The second and third relations were respectively with (Interpersonal manners) and (Time spent with doctor). From health care dimensions at the level of significance of $(0.01)$, they were $(0.29)$ and $(0.25)$ that means the information published on the page doesn't show personal manners of doctor, but it seems a weak relation as a result of response of the doctor in charge of the Center to some inquiries from page's viewers, not giving them time to discuss their cases .the dimensions (Financial aspects, Accessibility and convenience) have not achieved any correlation because the center e-page doesn't discuss these two dimensions in any way and does not give any information about them. Table (4) shows the relations

Table (4) the correlation among variables

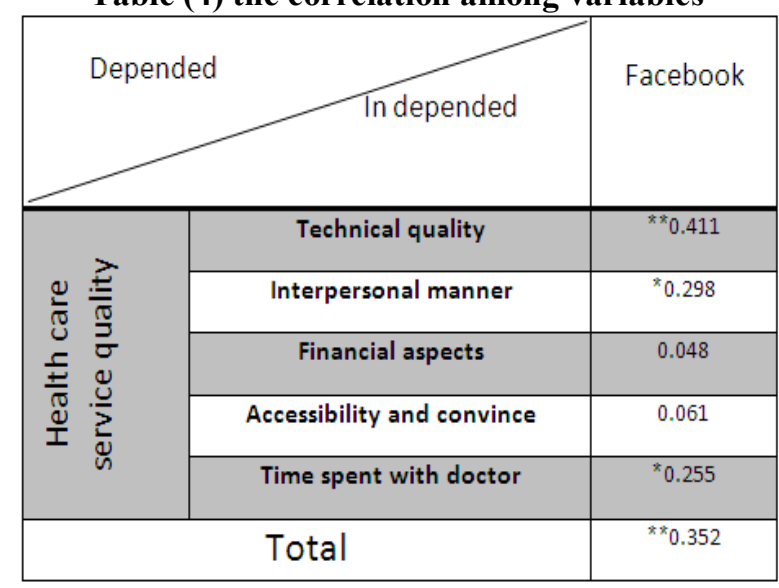




\section{Third: Analysis of Regression among Variables}

The statistical analysis was performed by using simple linear regression and results obtained are explained in Table (5) which shows there is no effective relation between Facebook (as social media web) and healthcare service in general, that invalidates the second main hypothesis which states there is effective relationship of significance between Facebook and the quality of healthcare service. At the dimension level, , no effective relation is achieved among the first main dimension (Facebook) and the sub dimension of healthcare service (interpersonal manners, Financial aspects, Accessibility and convince, Time spent with doctor) that shows the page on the Facebook doesn't have effect on the dimensions listed above, but one effective relation is achieved with (technological quality) dimension, the patient view shown on the Facebook page of the Center and the information about the technique of treatment at the Center have effect on the health service quality.

The interview with D.Muhannad AL-Mayali and the information we got show the limited effect of epage on his work and the e-page is exclusively used to give information about Center address and some simple medical information, in addition describe the techniques used in treatment because the eyes are sensitive part in human body. The Center can't give prescription or make diagnosis of the eye problem without physical examination

The interview with D.Muhannad AL-Mayali and the information we get from him showing the limiting of e-page effect on his work and exclusiveness to give information about center address and some simple medical info, in additional describe the technics of treatment no more because the eyes sensitive part in human body can't give Prescription or diagnosis the eye problem without scrutiny.

Table (5) Regression among variables

\begin{tabular}{|c|c|c|c|c|c|c|c|c|c|c|c|c|c|c|c|c|c|c|}
\hline \multirow{2}{*}{$\begin{array}{l}\text { Health } \\
\text { care } \\
\text { service } \\
\text { dimensions }\end{array}$} & \multicolumn{3}{|c|}{$\begin{array}{l}\text { Technical } \\
\text { quality }\end{array}$} & \multicolumn{3}{|c|}{$\begin{array}{l}\text { Interpersonal } \\
\text { manner }\end{array}$} & \multicolumn{3}{|c|}{$\begin{array}{c}\text { Financial } \\
\text { aspects }\end{array}$} & \multicolumn{3}{|c|}{$\begin{array}{l}\text { Accessibility } \\
\text { and convince }\end{array}$} & \multicolumn{3}{|c|}{$\begin{array}{l}\text { Time spent } \\
\text { with doctor }\end{array}$} & \multicolumn{3}{|c|}{ Total } \\
\hline & $\bar{F}$ & $\overline{R^{2}}$ & $\bar{B}$ & $\bar{F}$ & $R^{2}$ & $\bar{\beta}$ & $\bar{F}$ & $\overline{R^{2}}$ & $\bar{\beta}$ & $\mathbf{F}$ & $R^{2}$ & $\beta$ & $\mathrm{F}$ & $R^{2}$ & $\beta$ & $\mathrm{F}$ & $R^{2}$ & $\beta$ \\
\hline Facebook & 11.7 & 0.16 & 0.41 & 5.63 & 0.98 & 0.29 & 0.13 & 0.002 & 0.04 & 0.22 & 0.004 & 0.06 & 4.04 & 0.07 & 0.25 & 8.19 & 0.12 & 0.35 \\
\hline
\end{tabular}

Fourth: analysis of the E- form Results

In order to reach results more realistic and consistent with real work e-form was prepared, containing many questions to find out the real reasons of fans connection with Center page on Facebook. The results are as follows

The fan numbers during the course of the study reached (78500), of whom (73.81\%) visit Facebook daily ,and (42.86\%) visit the page sometimes, and (33.33\%) visit it always. That means the fans aren't systematically following-up the page and its updating. The manager of the Center sees the reason for unsystematic updating of the information on the page is because he manages it and there no person specialist working full-time to manage the page.

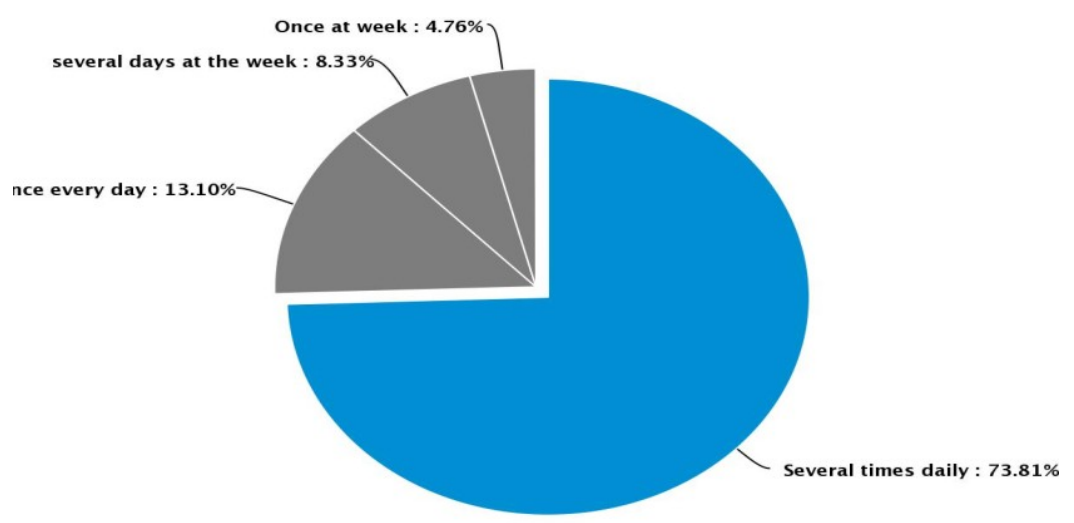

Chart (1) How often you visit Facebook? 


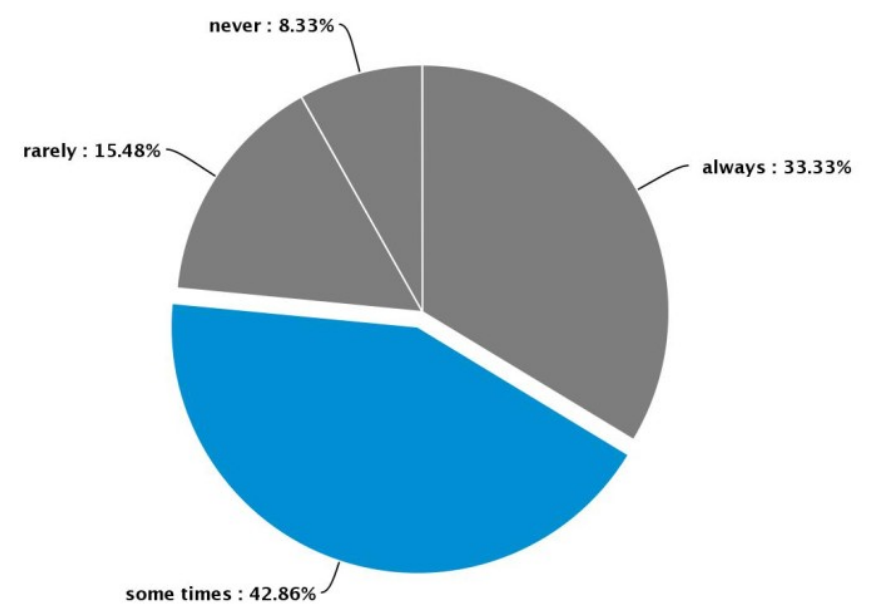

Chart (2) How often you visit page center on Facebook?

The reasons for visiting the page by fans are $(65.65 \%)$ visit it to get the information about service provided by the Center. Thus one of goals set by the manager to have is achieved by setting up the e-page that gives definition and advertisement to the center.

(51.81\%) consider the Center distinctive with the service presented, and the offers advertised are considered encouraging factor to visit the Center gaining an Acceptable percent of (36.14\%). the charts below show the results

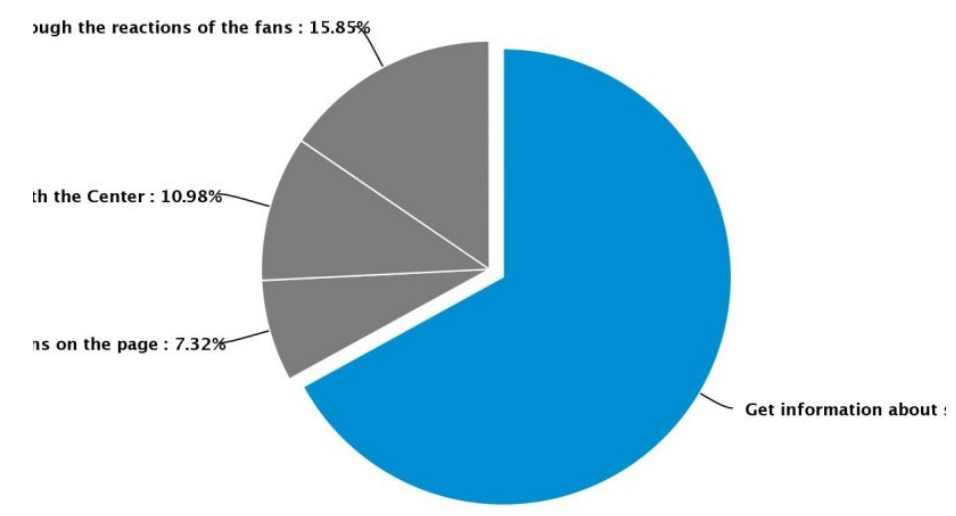

Chart (3) What the reason to like AL-Baseer center page?

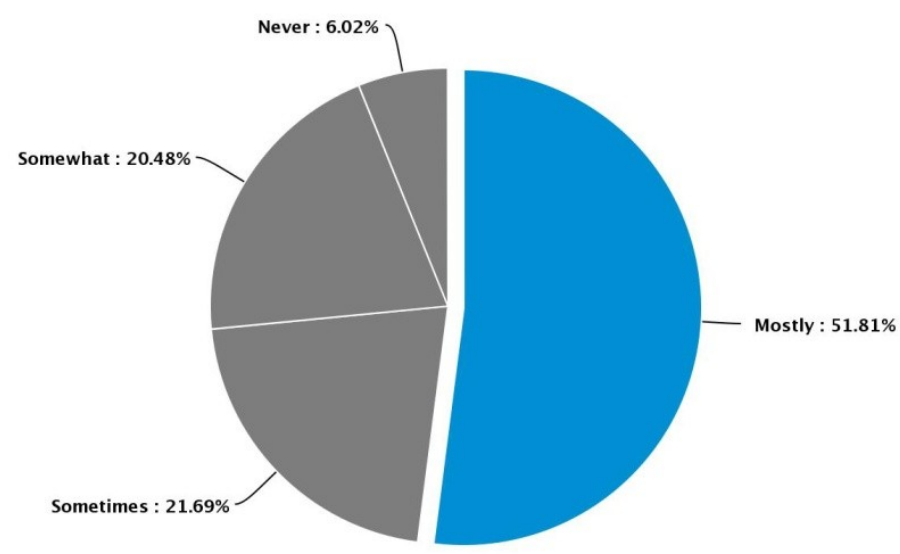

Chart (4) Are you seeing the center distinctive by service provided? 


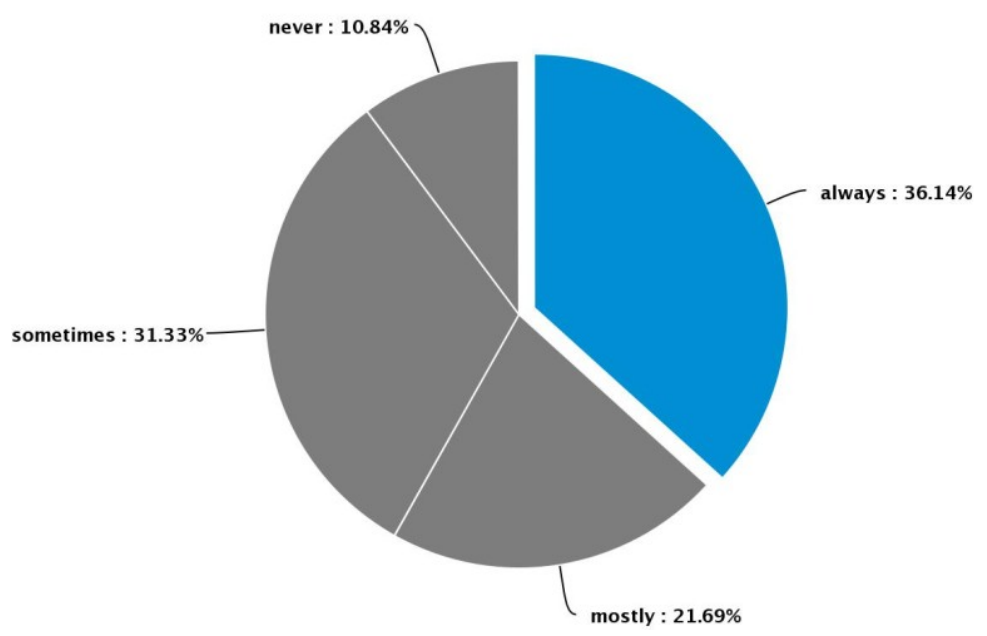

Chart (5) Encourages offers made by the Center on advertised on the page to visit on the ground and get services

These answers agree with real factual results, especialy regarding the page role in providing information about techniques used in treatment and defining the Center. But we found a large margin between visitors to Center page and visitors know the center by e-page during study time period

\section{Conclusions:}

1-Doctor friendly treatment with patients creates a sense of relief leading them to repeat the visit when they need and not search for alternative.

2-Balanced financial cost patient pays compared with those of competitors in the same sector is a good method to attract more customers.

3-The information published on the page is accurate about the center real work especially about techniques used in treatment and performing offers advertised.

4-The longer time spent by the doctor with each patient, the confidence is built.

5-Highly systematic method used to determine appointments reduces bottlenecks and waiting time.

6-Social media have limited impact on health care service quality.

\section{Recommendations}

1- Giving attention to questions asked by viewers on the page will certainly create a good impression, making people visit the Center.

2- Updating the e-page periodically, and posting information, photos and videos about Center work build and foster trust relation with customers.

3- Initiating appointment making by e-page will simplify access to the Center and make people think the Center is well advanced.

\section{References}

[1]. Ansari-Dunkes, Jasmin, Enckevort, Kaya Van (2013), Facebook and Brand equity, Umeå University.

[2]. Arah, Onyebuchi A, Westert Gert p, Hurst, Jeremy, Klazinga Niek s (2006), A conceptual framework for the OECD health care quality indicators project, international journal for quality in health care, p 5-13.

[3]. Essiam, Joshua Ofori (2013), service quality and patients satisfaction with healthcare delivery: empirical evidence from patients of the outpatient department of a public university hospital in Ghana, European journal of business and management, vol.5,no.28, p.52-59.

[4]. Filippos, Gavrilakis , Kalliopi, Makropoulou (2013), Strategic renewal through social media marketing an exploratory study of challenges and opportunities of companies in Swedish rural areas, JÖNKÖPING international business school, JÖNKÖPING university.

[5]. Korosuo, Saku (2013), Social media as a marketing tool for extreme- sport oriented companies, UMEA University.

[6]. Marshall, Grant N, Hays ,Ron D (1994), The patient satisfaction questionnaire short-form (psq-18), RAND, Santa Monica, p1-39.

[7]. Oxwall, Amanda, Zander, Tove (2012), In Facebook we trust a case study of consumer relationship \& Facebook, Kristianstad university college international business and economics program.

[8]. Purcărea, Victor Lorin, Gheorghe, Iuliana Raluca, Petrescu, Consuela Mădălina (2013), The assessment of perceived service quality of public health care service in Romania using the SERVQUAL scale, Science Direct, p573-585.

[9]. Sintset, Sylviane(2012), The impact of social networking on customer loyalty Facebook case, Linnaeus university.

[10]. Untachai, Subcht(2013), Modeling service quality in hospital as a second order factor, Thailand, Science Direct, vol. 88,p118133. 